\title{
Germinação e formação de mudas de alface em diferentes níveis de salinidade de água
}

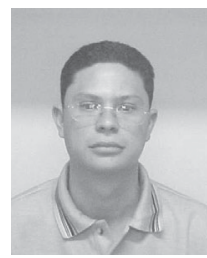

\author{
Sergio B. A. Viana ${ }^{1}$, Pedro D. Fernandes ${ }^{2} \&$ Hans R. Gheyi ${ }^{3}$ \\ 1 DEAg/UFPB/CCT. CEP 58109-970, Campina Grande, PB. Fone (83) 333-8232, E-mail: sbaviana@bol.com.br (Foto) \\ 2 DEAg/CCT/UFPB. Fone (83) 310-1285, Fax (83) 310-1307. E-mail: pdantas@deag.ufpb.br \\ ${ }^{3}$ DEAg/CCT/UFPB. Telefax (83) 310-1056. E-mail: hans@deag.ufpb.br
}

Protocolo $003-12 / 01 / 2001$

\begin{abstract}
Resumo: Tendo em vista a magnitude dos problemas de salinidade na região Nordeste e a inexistência de indicativos de tolerância da cv. Elba de alface à salinidade, estudou-se, no delineamento inteiramente casualizado, os efeitos de 6 níveis de condutividade elétrica da água de irrigação (CEa), entre 0,3 e 3,8 dS m-1, sobre o vigor e a formação de mudas de alface. As águas foram preparadas mantendo-se proporção equivalente $7: 2: 1$, respectivamente, entre $\mathrm{Na}: \mathrm{Ca}: \mathrm{Mg}$. Todas as variáveis estudadas foram afetadas pela salinidade, tanto na germinação quanto em fase de muda, no entanto, CEa de 3,8 $\mathrm{dS} \mathrm{m}^{-1}$, considerada como de elevada restrição agrícola, proporcionou $90 \%$ de germinação relativa, $61 \%$ de vigor de plântulas (média entre as variáveis avaliadas) e mudas com $50 \%$ de crescimento, podendo-se classificar a alface como moderadamente tolerante à salinidade na germinação e moderadamente sensível na fase de plântula e de muda.
\end{abstract}

Palavras-chave: vigor, velocidade de emergência, fitomassa, Lactuca sativa L.

\section{Germination and seedling development of lettuce in relation to water salinity}

\begin{abstract}
Keeping in view the magnitude of the salinity problems in the Northeast region and the inexistence of salinity tolerance indications for lettuce cv. Elba, an experiment was carried out in a completely randomized design, with the objective of studying the effects of 6 levels of electrical conductivity of the irrigation water (ECw) varying from 0.3 to $3.8 \mathrm{dS} \mathrm{m}^{-1}$ on the vigor and formation of lettuce seedling. The irrigation water of desired ECw was prepared maintaining equivalent proportion of 7:2:1, among $\mathrm{Na:Ca:Mg}$, respectively. All the variables studied were affected by salinity during germination and in the seedling stage, however ECw of $3.8 \mathrm{dS} \mathrm{m}^{-1}$, considered as being of severe agricultural restriction, provided on average $90 \%$ of relative germination, $61 \%$ of vigor and seedling with $50 \%$ growth, permits to classify lettuce as moderately tolerant to salinity during germination and moderately sensitive in the seedling phase.
\end{abstract}

Key words: vigor, vigor index, phytomass, Lactuca sativa L.

\section{INTRODUÇÃO}

Entre os fatores que afetam o desenvolvimento das plantas, constam os problemas de salinidade decorrentes da acumulação de sais solúveis no solo, sobretudo devido a um manejo inadequado da água de irrigação.

O estresse salino inibe o crescimento das plantas, por reduzir o potencial osmótico da solução do solo, restringindo a disponibilidade de água e/ou por acumulação excessiva de íons nos tecidos vegetais, podendo, ainda, ocasionar toxicidade iônica, desequilíbrio nutricional, ou ambos (Boursier \& Lauchli, 1990). O grau em que cada um dos componentes do estresse influencia o crescimento das plantas, é dependente de muitos fatores, dentre outros da espécie vegetal, cultivar e estádio fenológico, composição salina do meio, intensidade e duração do estresse e das condições edafo-climáticas (Cramer et al., 1994).

Segundo Maas (1984) e Ayers \& Westcot (1991), a alface é "moderadamente sensível" à salinidade, tendo a produção decrescida em $13 \%$, por aumento unitário de condutividade elétrica do extrato de saturação (CEes) acima de 1,3 $\mathrm{dS} \mathrm{m}^{-1}$; em termos de condutividade elétrica de água (CEa) o limiar seria de $0,9 \mathrm{dS} \mathrm{m}^{-1}$, considerando-se a relação entre CEa e CEes, proposta por Ayers \& Westcot (1991) para fração de lixiviação entre 0,15 e 0,20 .

No Brasil, apesar da importância da alface que, já em 1986, era a sexta hortaliça em valor de produção e a oitava em termos de volume produzido (Nadal et al., 1986), são poucos os trabalhos de pesquisa envolvendo estresse salino em alface, 
sobretudo na região Nordeste. Os poucos estudos existentes em nível nacional, foram realizados na região Sudeste (Ferreira et al., 1998; Blanco et al., 1999; Silva et al., 1999; Gervásio et al., 2000), onde, além de serem distintas as condições ambientais, diferentes são as variedades cultivadas (Filgueira, 1982). Vale ressaltar que não foi encontrada, na literatura, qualquer referência sobre a germinação da alface em condições de estresse salino.

Ante a carência de resultados de pesquisa com a cultura da alface, sobretudo na região Nordeste, em que, via de regra, as águas disponíveis para irrigação contêm teores relativamente elevados de sais (Audry \& Suassuna, 1995), este trabalho se propôs estudar os efeitos da salinidade da água de irrigação sobre a germinação e a formação de mudas de alface, cv. 'Elba', a mais plantada no Estado da Paraíba.

\section{MATERIAL E MÉTODOS}

O experimento foi conduzido em casa-de-vegetação localizada no Campus II da Universidade Federal da Paraíba, em Campina Grande, PB, durante o período compreendido entre novembro de 1999 e janeiro de 2000.

Foram estudados, em delineamento inteiramente casualizado, os efeitos de seis níveis de condutividade elétrica da água de irrigação, variando de 0,3 a $3,8 \mathrm{dS} \mathrm{m}^{-1}$, denominados $\mathrm{S}_{1}$ a $_{6}$ (com incremento de $0,7 \mathrm{dS} \mathrm{m}^{-1}$ entre os tratamentos), sobre o vigor (germinação e plântulas) e a formação de mudas da cv. de alface 'Elba', até 46 dias pós semeio, sendo o ensaio composto de cinco repetições, cada uma com cinco recipientes.

Os recipientes utilizados foram copos plásticos de $150 \mathrm{~mL}$ de capacidade, perfurados na base para permitir drenagem, preenchidos com $130 \mathrm{~g}$ de um substrato composto de 4 partes de húmus de minhoca +1 parte de um material de solo tipo Podzólico, franco-arenoso, não salino e não sódico + 1 parte de areia lavada, com base em peso. As características químicas e físico-hídricas do material de solo utilizado, obtidas conforme as metodologias propostas por Richards (1954), se encontram na Tabela 1 .

Tabela 1. Características químicas e físico-hídricas do material de solo (profundidade $0-20 \mathrm{~cm}$ ) utilizado

\begin{tabular}{lr}
\hline Atributo & \multicolumn{1}{c}{ Valor } \\
\hline Densidade aparente $-\mathrm{kg} \mathrm{dm}^{-3}$ & 1,37 \\
Classificação textural & $\begin{array}{r}\text { Franco-arenoso } \\
\text { Classificação para salinidade/sodicidade }\end{array}$ \\
Extrato de saturação: & Não salino, não sódico \\
pH & 4,54 \\
Condutividade elétrica - dS m${ }^{-1}$ a $25^{\circ} \mathrm{C}$ & 0,50 \\
$\mathrm{RAS}^{*}-\left(\mathrm{mmol} \mathrm{L}^{-1}\right)^{0,5}$ & 1,84 \\
Complexo sortivo - $\mathrm{cmol}_{\mathrm{c}} \mathrm{kg}^{-1}$ & \\
$\mathrm{H}+\mathrm{Al}$ & 2,72 \\
$\mathrm{Ca}$ & 0,38 \\
$\mathrm{Mg}$ & 0,74 \\
$\mathrm{Na}$ & 0,20 \\
$\mathrm{~K}$ & 0,06 \\
$\mathrm{CTC}$ & 4,10 \\
Saturação de bases $(\mathrm{V})$ - \% & 33,66 \\
Retenção de umidade - \% (base em peso) & \\
$10,13 \mathrm{kPa}$ & 8,72 \\
$1519,87 \mathrm{kPa}$ & 2,73 \\
\hline Relação de adsorção de sódio
\end{tabular}

No material de solo foi realizada calagem pelo método da "saturação de bases", para elevar o pH a 6,25, mediante elevação da percentagem de saturação de bases (V) para 70\% (Osaki, 1991), utilizando-se de hidróxido de cálcio. Seguindo-se a metodologia proposta por Lopes \& Guidolin (1989), efetuou-se, também, adubação construtiva de fertilidade para fósforo e potássio, com o intuito de se elevar a concentração de $\mathrm{P}$ no material de solo para $12 \mathrm{mg} \mathrm{kg}^{-1}$ e a participação do $\mathrm{K}$ na CTC efetiva para $3 \%$, sendo utilizados os adubos superfosfato simples e cloreto de potássio.

A seguir, após se efetuar o traço do substrato na proporção anteriormente abordada $(4: 1: 1)$, realizaram-se a desinfecção e desinfestação do substrato com "brometo de metila", na dose recomendada pelo fabricante $\left(150 \mathrm{~mL} \mathrm{~m}^{-3}\right.$ de material do solo).

As águas utilizadas nas irrigações foram preparadas mediante adição de $\mathrm{NaCl}, \mathrm{CaCl}_{2}$ e $\mathrm{MgCl}_{2}$, em quantidades de forma a se obter a $\mathrm{CEa}$ de cada tratamento, com proporção equivalente de 7:2:1, respectivamente entre $\mathrm{Na}, \mathrm{Ca}$ e $\mathrm{Mg}$, relação esta predominante nas águas de alta salinidade utilizadas para irrigação no Nordeste, conforme Medeiros (1992).

Foram semeadas, a uma profundidade de $0,5 \mathrm{~cm}$, oito sementes em cada recipiente. No dia anterior à semeadura, cada recipiente recebeu $40 \mathrm{~mL}$ da respectiva água. As irrigações foram efetuadas duas vezes ao dia, pela manhã $(9: 00 \mathrm{~h})$ e ao final da tarde $(18: 00 \mathrm{~h})$, com $12 \mathrm{~mL}$ da respectiva água de irrigação, de forma a proporcionar drenagem. Houve avaliação da drenagem uma vez por dia, quando se coletava, em bandeja plástica, a água de drenagem proveniente de 10 recipientes por tratamento para posterior mensuração da condutividade elétrica (CEad), sendo os recipientes colocados na bandeja por ocasião da irrigação (uma bandeja por tratamento).

O desbaste foi realizado no $25^{\circ}$ dia, deixando-se duas plântulas por vaso, justamente as que representavam a média da respectiva repetição; em seguida, foi iniciada a execução do plano de adubação com: solução de nitrato de cálcio a $20 \mathrm{mg} \mathrm{L}^{-1}$ de $\mathrm{N}$, na dose de $10 \mathrm{~mL}_{\text {vaso }}{ }^{-1}$, aos 27, 30, 33 e 41 dias após semeadura (DAS); adubo foliar comercial Albatrós* a 1,8 g L-1, aos 29, 32 e 35 DAS; solução de uréia a $0,25 \%$, na base de $10 \mathrm{~mL} \mathrm{vaso}^{-1}$, aos 36,40 e $42 \mathrm{DAS}$ e, solução de nitrato de potássio a $20 \mathrm{mg} \mathrm{L}^{-1} \mathrm{de}$ $\mathrm{K}$, também com $10 \mathrm{~mL}$ vaso $^{-1}$, aos 39 e $43 \mathrm{DAS}$, garantindo às plantas condições satisfatórias de crescimento.

Procedeu-se diariamente a contagem do número de sementes germinadas por recipiente. Com os dados, avaliaram-se o Índice de Velocidade de Emergência (IVE) aos 7 e 14 dias após a semeadura (DAS), conforme a Eq. 1, contida em Vieira \& Carvalho (1994) e a percentagem de germinação (PG) aos 7 DAS, conforme recomendação de Brasil (1992) e, também, aos 10 e 14 DAS; as duas últimas avaliações de PG foram incluídas por se estar trabalhando com salinidade que, normalmente, atrasa a germinação.

$$
\operatorname{IVE}=\frac{E_{1}}{N_{1}}+\frac{E_{2}}{N_{2}}+\ldots+\frac{E_{n}}{N_{n}}
$$

em que:

$\mathrm{E}_{1}, \mathrm{E}_{2}, \mathrm{E}_{\mathrm{n}}$ - número de plântulas emergidas, computadas à primeira, segunda, ... e última contagem

\footnotetext{
* Composição do adubo: $\mathrm{N}-7 \%$; $\mathrm{P}_{2} \mathrm{O}_{5}-17 \%$; $\mathrm{K}_{2} \mathrm{O}-35 \%$; $\mathrm{MgO}-3 \%$; $\mathrm{Ca}-0,10 \%$; $\mathrm{B}-0,02 \%$;
} $\mathrm{Cu}-0,02 \%$; Fe - $0,15 \%$; Mn - 0,10\%; Zn - 0,02\%; Mo - 0,0005\% 
$\mathrm{N}_{1}, \mathrm{~N}_{2}, \mathrm{~N}_{\mathrm{n}}$ - número de dias da semeadura à primeira, segunda, ... e última contagem.

O estudo de vigor de plântulas foi efetuado no $7^{\circ}$ e no $14^{\circ}$ DAS, utilizando-se de 25 plântulas/tratamento ( 5 por repetição), sendo avaliadas as variáveis fitomassa seca da parte aérea por planta (FSPA) e fitomassa seca de raiz (FSR). A avaliação das mudas foi realizada no $46^{\circ}$ DAS, a partir de 10 plantas por tratamento ( 2 por repetição) estudando-se as mesmas variáveis descritas para o estudo de vigor de plântulas, acrescendo-se o número de folhas por planta (NF). Avaliou-se, também, a evapotranspiração relativa (ETr) nos períodos 0 a 7, 0 a 14 e 0 a 46 DAS, considerada como a diferença entre o volume de água aplicado e o drenado.

As variáveis foram avaliadas utilizando-se de teste "F" e análise de regressão, linear e quadrática (Ferreira, 1991).

\section{RESULTADOS E DISCUSSÃO}

\section{Vigor de germinação}

Verifica-se na Figura 1A e B que a salinidade afetou significativamente $(\mathrm{p}<0,01)$ a germinação, com efeito quadrático em todas as avaliações. No entanto, de acordo com a equação de regressão exposta para 14 DAS (Figura 1A), só houve decréscimo relativo do $\mathrm{PG}$, comparado ao nível mais baixo de salinidade estudado $\left(\mathrm{S}_{1}\right)$, quando a $\mathrm{CEa}$ excedeu a $2,81 \mathrm{dS} \mathrm{m}^{-1}$, sendo este valor, em termos de IVE, de 2,42 $\mathrm{dS} \mathrm{m}^{-1}$ (Figura 1B). Apesar de ter havido efeito significativo da salinidade sobre a germinação, nota-se que água de severa restrição agrícola (Ayers \& Westcot, 1991) como 3,8 dS m $\left(\mathrm{S}_{6}\right)$ proporcionou aproximadamente $90 \%$ da germinação ocorrida em $\mathrm{S}_{1}$, denotando ser a alface moderadamente tolerante à salinidade na germinação, superando as expectativas, devido tratar-se de fase inicial, quando a maioria das culturas é sensível e, também, por haver indicações (Ayers \& Westcot, 1991) de ser esta hortaliça 'moderadamente sensível' à salinidade.

Observa-se que o valor crítico de condutividade elétrica da água de irrigação para o IVE foi inferior ao obtido em termos de PG, por ter sido o efeito da salinidade mais intenso sobre a velocidade de emergência, fato comprovado pelos maiores decréscimos relativos ocasionados por $\mathrm{S}_{5}$ e $\mathrm{S}_{6}$ sobre o IVE, respectivamente de 6,63 e $16,77 \%$, enquanto sobre o PG esses valores foram de 2,21 e 9,58\%. Sabe-se que a salinidade, ao reduzir o potencial osmótico do meio, aumenta o tempo de embebição de água pelas sementes, ocasionando, inicialmente, o prolongamento do período de emergência da plântula (Pizarro, 1985), fato verificado no presente trabalho com CEa de até $2,42 \mathrm{dS} \mathrm{m}^{-1}$. Ainda segundo o citado autor, quando a redução do potencial osmótico é intensificada, ocorre inibição do processo germinativo, como aconteceu quando da irrigação com água de CE superior a $2,81 \mathrm{dS} \mathrm{m}^{-1}$ nesta pesquisa; além do mais, a absorção excessiva de íons como $\mathrm{Na}$ e $\mathrm{Cl}$ ocasiona diminuição da intensidade respiratória e da atividade de algumas enzimas envolvidas na germinação (Azimov, 1973), restringindo a obtenção de energia para o processo de divisão celular e crescimento do eixo embrionário.
A.

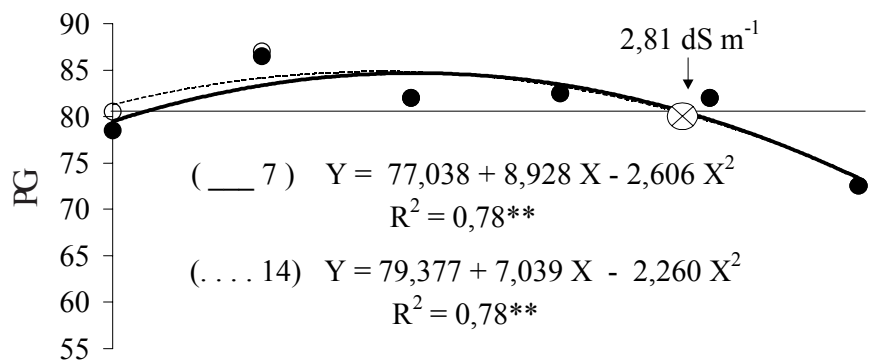

B.

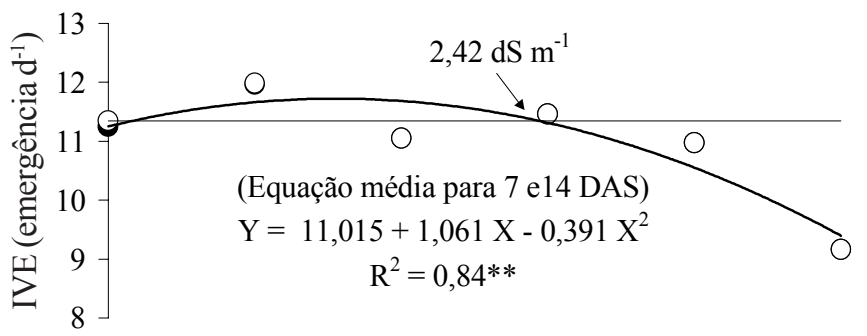

C.

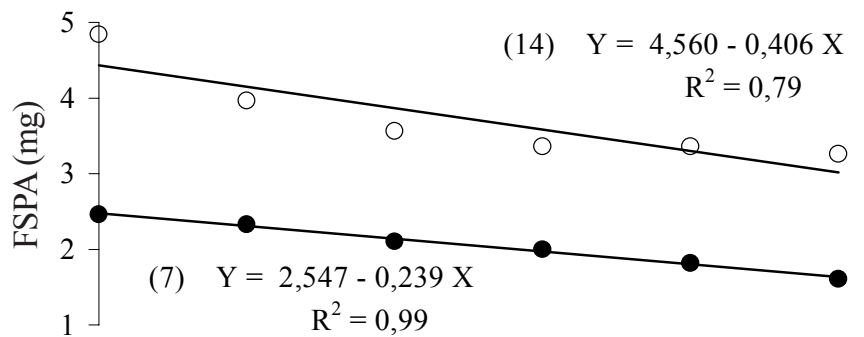

D.
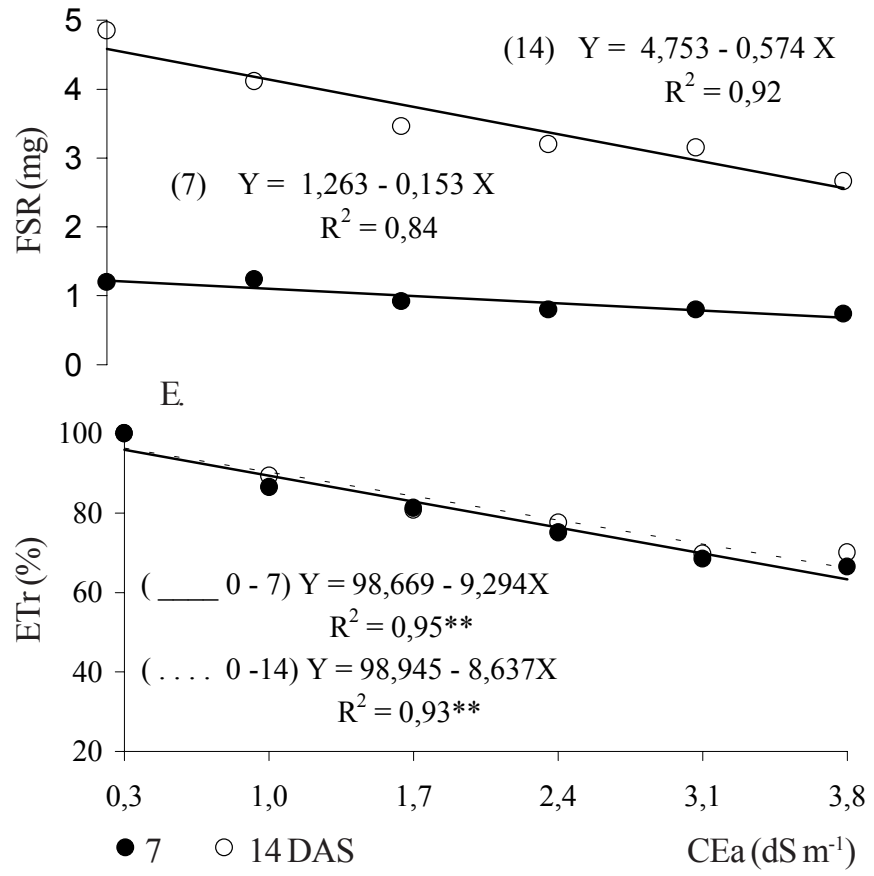

Figura 1. Percentagem de germinação (PG), índice de velocidade de emergência (IVE), fitomassa seca da parte aérea (FSPA) e de raiz (FSR) aos 7 e 14 dias após semeadura (DAS) da alface e evapotranspiração relativa (ETr) média em 0 - 7 e 0 - 14 DAS, em função da salinidade da água de irrigação (CEa)

Vários autores têm constatado, igualmente, redução da velocidade de emergência em outras espécies, devido à diminuição do potencial osmótico, quer por meio de tratamentos 
de salinidade, como no caso de coentro, estudado por Filgueira (1993), quer de simulação de estresse induzido por agentes osmóticos, como nos casos de Magalhães \& Carelli (1972) em feijão, Sharma (1976) em forrageiras, e Pereira (1997) em algodão.

Observa-se, através da Figura 1A, pequena variação do percentual de germinação a partir de uma semana, com leve incremento apenas nos níveis $\mathrm{S}_{1}$ e $\mathrm{S}_{2}$; para os demais tratamentos não houve qualquer aumento após o período de contagem de 7 DAS recomendado por Brasil (1992) para teste de germinação em alface. Verifica-se, também, que em todos os tratamentos foram obtidos valores médios de PG acima do limite mínimo, que é de 70\% (Filgueira, 1982).

\section{Vigor de plântulas}

A produção de fitomassa foi linearmente afetada $(p<0,01)$ pela salinidade da água de irrigação (Figura $1 \mathrm{C}$ e D) tanto aos 7 quanto aos 14 DAS. Conforme as equações de regressão obtidas, o incremento unitário da CEa ocasionou decréscimo relativo, comparado a $S_{1}$, de 9,66 e $12,54 \%$, respectivamente, sobre a FSPA e a FSR aos 7 DAS, e de 9,16 e $12,53 \%$ aos 14 DAS; verifica-se que no nível mais alto de CEa estudado, normalmente considerado impróprio ao uso em irrigação na maioria das culturas, sobretudo em fase inicial de desenvolvimento, foram obtidos $67 \%$ da FSPA e $56 \%$ da FSR conseguida com CEa de $0,3 \mathrm{dS} \mathrm{m}^{-1}$. Observa-se que nas duas avaliações houve maior prejuízo sobre as raízes, fato constatado em estudos de mesma natureza envolvendo outras culturas (Amorim, 1994, em alho; Marinho et al., 1998, em abacaxi, entre outros), embora alguns trabalhos encontrados na literatura reportem, de forma genérica, que a salinidade inibe menos o crescimento radicular que o da parte aérea (Maas \& Hoffman, 1977; Shannon, 1979).

Nota-se, na Figura 1E, que a evapotranspiração relativa decresceu na base de 9,29 e 8,63\% por incremento unitário de $\mathrm{CEa}$, respectivamente nos períodos 0 - 7 e 0 - 14 DAS, seguindo, portanto, uma tendência bastante semelhante à ocorrida com a FSPA, inclusive em termos de diminuição da taxa de decréscimo entre os períodos considerados, confirmando a relação direta entre evapotranspiração e crescimento das culturas abordada em Doorenbos \& Kassam (1994).

Comparando-se os efeitos da salinidade sobre as variáveis consideradas nos estudos de vigor, verifica-se ter havido efeito mais intenso sobre o crescimento de plântulas (FSPA e FSR) que sobre os índices de germinação (PG e IVE). Considerando-se a média dos decrementos ocasionados por $\mathrm{S}_{6}$ sobre a FSPA e FSR, confirma-se a classificação encontrada na literatura (Ayers \& Westcot, 1991) para esta hortaliça, ou seja, 'moderadamente sensível' à salinidade.

\section{Formação de mudas}

A salinidade afetou significativamente $(p<0,01)$ todas as variáveis estudadas aos 46 DAS (Figura 2A, B e C), com efeito linear sobre o número de folhas (NF) e fitomassa seca da parte aérea (FSPA), apesar de se notar, pela dispersão dos pontos, uma certa manutenção dos níveis de acúmulo de FSPA até $\mathrm{S}_{3}$. Em termos de fitomassa seca de raiz (FSR) o efeito foi quadrático.

De acordo com as equações expostas na Figura 2, o NF foi reduzido, relativamente a $\mathrm{S}_{1}$, em $9,1 \%$ por incremento unitário de CEa, enquanto a FSPA decresceu na base de $14,7 \%$; no nível
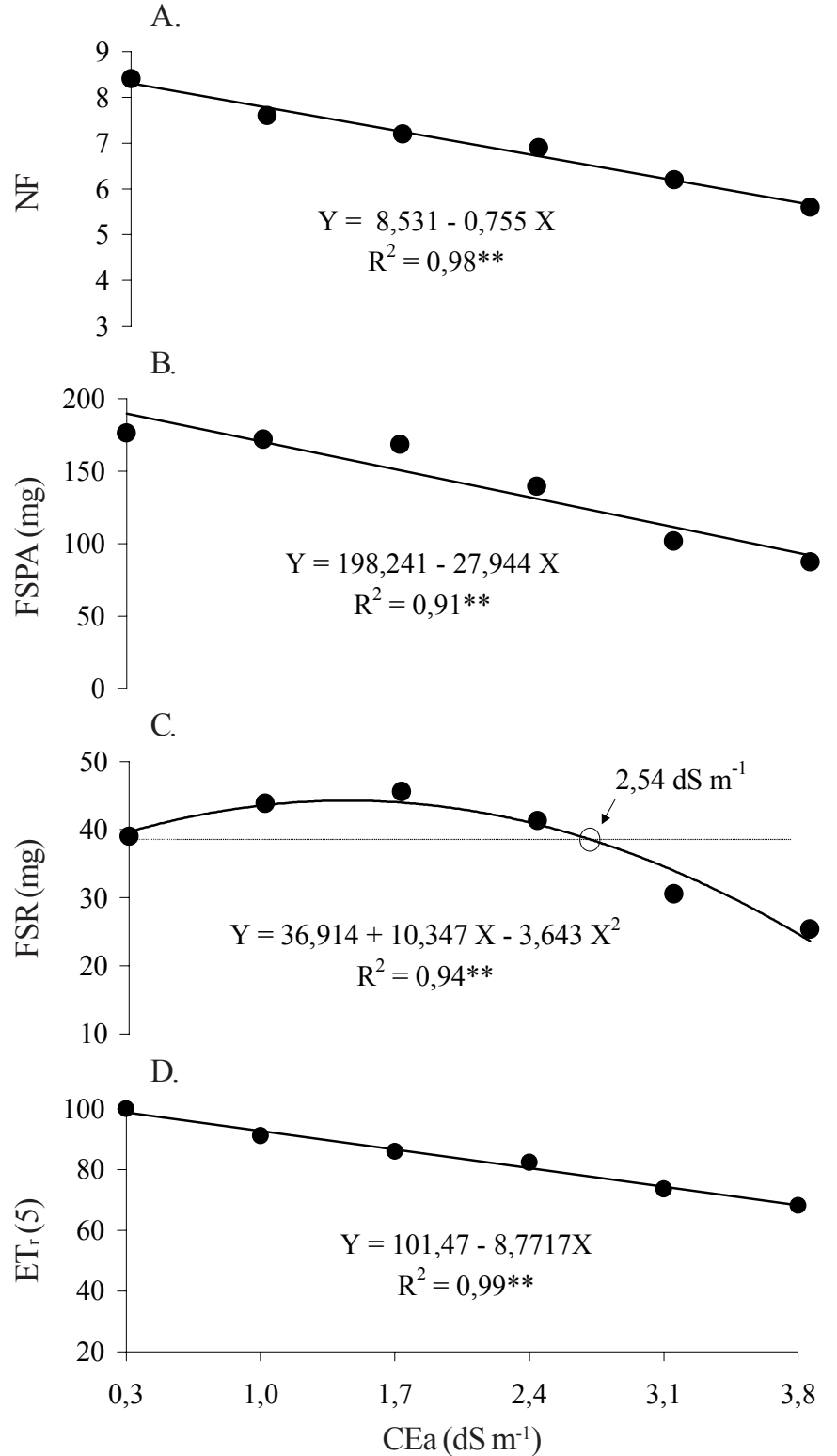

Figura 2. Número de folhas (NF), fitomassa seca da parte aérea (FSPA) e de raiz (FSR) aos 46 dias após semeadura (DAS) e evapotranspiração relativa (ETr) média no período 0 - 46 DAS, em função da salinidade da água de irrigação (CEa)

mais alto de salinidade estudado $\left(3,8 \mathrm{dS} \mathrm{m}^{-1}\right)$ houve redução relativa (comparada a $\mathrm{S}_{1}$ ) de 31,8 e $51,5 \%$, respectivamente sobre o NF e a FSPA. Da mesma forma, a evapotranspiração relativa (ETr) decresceu linearmente com o aumento da CEa (Figura 2E), porém, em menor intensidade $(8,77 \%$ por aumento unitário de $\mathrm{CEa})$, fato este observado por Soares et al. (2001*) em estudo de mesma natureza com maracujazeiro amarelo. Para a fitomassa seca de raiz (FSR), conforme a equação de regressão, significativa em nível de 0,01 de probabilidade (Figura 2D), só houve decréscimo relativo quando a CEa excedeu a $2,54 \mathrm{dS} \mathrm{m}^{-1}$, acarretando $40,47 \%$ de redução relativa $\mathrm{em}_{6}$. Com base nos decrementos ocorridos, a alface pode ser classificada como 'moderadamente sensível' à salinidade, em fase de muda, confirmando a classificação encontrada na literatura (Ayers \& Westcot, 1991).

* Soares, F.A.L.; Gheyi, H.R.; Viana, S.B.A.; Uyeda, C.A.; Fernandes, P.D. Desenvolvimento inicial de maracujazeiro amarelo em função da salinidade da água. Fevereiro de 2001. (Comunicação pessoal) 
Comparando-se as taxas de decréscimo de FSPA e ETr por aumento unitário de CEa ocorridas aos 14 DAS $(9,16$ e 8,63\% respectivamente) com os valores discutidos para 46 DAS, nota-se que o efeito da salinidade sobre o crescimento das plantas aumentou em $60 \%$ de 14 para 46 DAS, enquanto a taxa de decréscimo de consumo de água se manteve praticamente inalterada, ocorrendo apenas um leve incremento de $1,6 \%$. Diante desse fato e tendo em vista a salinidade do solo ter entrado em equilíbrio a partir de 14 DAS, como pode ser observado pelos dados de CEad contidos na Tabela 2, verifica-se intensificação dos efeitos da salinidade, com redução da eficiência do uso da água pelas plantas entre $14 \mathrm{e}$ 46 DAS, uma característica de sensibilidade ao estresse.

Tabela 2. Valores médios de condutividade elétrica de água de drenagem (CEad) observados durante sete semanas após semeadura (SAS) para os diferentes níveis de condutividade elétrica da água de irrigação (CEa)

\begin{tabular}{ccccccc}
\hline \multirow{2}{*}{ SAS } & \multicolumn{5}{c}{ CEa $\left.(\mathrm{dS} \mathrm{m})^{-1}\right)$} \\
\cline { 2 - 7 } & 0,3 & 1,0 & 1,7 & 2,4 & 3,1 & 3,8 \\
\hline 1 & 1,17 & 1,66 & 2,34 & 3,09 & 3,77 & 4,51 \\
2 & 1,10 & 1,90 & 2,94 & 4,00 & 5,13 & 5,96 \\
3 & 0,99 & 1,96 & 3,13 & 4,21 & 5,33 & 6,28 \\
4 & 0,96 & 2,03 & 3,07 & 4,16 & 5,25 & 6,26 \\
5 & 0,95 & 1,90 & 2,95 & 3,96 & 5,27 & 6,29 \\
6 & 1,03 & 2,05 & 3,07 & 3,84 & 5,14 & 6,28 \\
7 & 1,02 & 2,03 & 3,05 & 3,87 & 5,20 & 6,26 \\
\hline Média & 1,03 & 1,92 & 2,91 & 3,88 & 4,98 & 5,93 \\
\hline
\end{tabular}

Os poucos trabalhos existentes na literatura, a respeito de estresse salino em alface, na fase inicial de desenvolvimento, evidenciam decréscimo de fitomassa com aumento da salinidade (Shannon et al., 1983; Cramer \& Spurr, 1986), como também, em fase de produção (Ferreira et al., 1998; Silva et al., 1999; Blanco et al., 1999; Gervásio et al., 2000).

Tendo em vista os decréscimos de FSPA e FSR abordados, constata-se que na avaliação final das mudas (46 DAS) o maior efeito depreciativo da salinidade ocorreu em termos de parte aérea (Figura 2B), sendo a diferença mais acentuada em $\mathrm{S}_{3}$ $\left(1,7 \mathrm{dS} \mathrm{m}^{-1}\right)$, onde a FSPA sofreu decréscimo de $20,6 \%$, ao passo que, para a FSR, houve incremento de quase $10 \%$. Desta forma, se no desenvolvimento inicial das plântulas, avaliado através dos estudos de vigor, a salinidade afetou mais o sistema radicular, aos 46 DAS o maior prejuízo ocorreu em termos de parte aérea.

Cramer \& Spurr (1986) estudando o efeito da salinidade da água em alface (cv. Climax) a partir da emissão da segunda folha acima do cotilédone e irrigando até 20 dias após, encontraram, também, maior sensibilidade da parte aérea, por não ter sido afetado o crescimento radicular com o aumento da salinidade até $40 \mathrm{~mol} \mathrm{~m}^{-3}\left(\mathrm{CE} \cong 4,0 \mathrm{dS} \mathrm{m}^{-1}\right)$ de $\mathrm{NaCl}$, ao passo que, nesse nível, a parte aérea sofreu redução relativa de $30 \%$.

Através da análise de regressão segmentada (modelo platô) aplicada aos dados relativos de FST aos 46 DAS (Figura 3), em função da CEes (média 0 - 46 DAS), esta estimada através da relação 'CEes = 0,5 x CEad', contida em Ayers \& Westcot (1991), verifica-se que o limite de CEes (salinidade limiar - SL) a partir do qual ocorreu decréscimo da FST, foi de 1,42 $\mathrm{dS} \mathrm{m}^{-1}$, seguido de taxa de decréscimo relativo de 32,01\% por aumento unitário de CEes. Desta forma, apesar de se ter obtido um valor de SL superior ao encontrado na literatura para alface (todo o ciclo) (Ayers \& Westcot, 1991), denotando-se maior tolerância, ainda assim a cv. Elba, em fase de muda, receberia a mesma classificação contida na citada referência, ou seja, 'moderadamente sensível'. Nota-se, na Tabela 2 que, logo após 14 dias, a CEad praticamente havia atingido o equilíbrio, de modo que os valores de CEes utilizados na análise de regressão segmentada, representam bem a condição de estresse a que as plantas estavam submetidas durante o experimento.

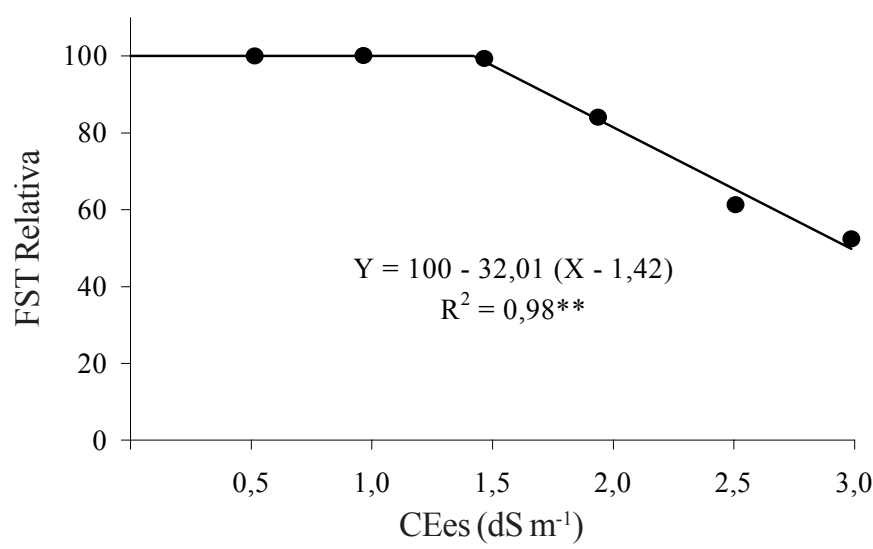

Figura 3. Fitomassa seca total (FST) da planta aos 46 dias em função da condutividade elétrica do extrato de saturação estimada $(\mathrm{CEes}=0,5 \mathrm{CEad})$

Apesar da taxa de decréscimo observada quando a CEes excedeu a $1,42 \mathrm{dS} \mathrm{m}^{-1}$, verifica-se que, com salinidade do solo (CEes) de aproximadamente $3 \mathrm{dS} \mathrm{m}^{-1}$ (CEa de $3,8 \mathrm{dS} \mathrm{m}^{-1}$ ) ainda houve $50 \%$ de crescimento das plantas, podendo-se, desta forma, usar água de $\mathrm{CE}<3,8 \mathrm{dS} \mathrm{m}^{-1}$ na produção de mudas de alface cv. Elba, com perspectiva de boa recuperação do crescimento após o transplantio, fato constatado por Viana et al. (2001), quando verificaram que a produtividade desta cultivar, a partir de mudas produzidas com CEa de 0,3 e de $3,1 \mathrm{dS} \mathrm{m}^{-1}$, foi estatisticamente igual, havendo, inclusive, maior eficiência de uso de água e superior taxa de crescimento para as plantas oriundas de mudas produzidas com água de $3,1 \mathrm{dS} \mathrm{m}^{-1}$. Alguns estudos têm evidenciado que o estresse salino em fase inicial confere às plantas o fenômeno de 'Hardening' traduzido para o português como 'endurecimento' salino, resultando em maior capacidade de adaptação da cultura à salinidade, posteriormente em campo (Manchanda \& Bhandhari, 1976, em trigo e cevada).

\section{CONCLUSÕES}

1. A alface Elba tolera água de até $2,8 \mathrm{dS} \mathrm{m}^{-1}$ sem redução de germinação; mas, o acúmulo de fitomassa nas plântulas, parte aérea e raiz, decresce linearmente com o incremento da condutividade elétrica da água (CEa) acima de $0,3 \mathrm{dS} \mathrm{m}^{-1}$.

2. Em fase de muda o efeito da salinidade entre partes da planta é diferenciado; a parte aérea decresce linearmente com o aumento da CEa, mas, o sistema radicular só é prejudicado quando a CEa excede a $2,54 \mathrm{dS} \mathrm{m}^{-1}$. 
3. A alface Elba tolera, em fase de muda, até $1,42 \mathrm{dS} \mathrm{m}^{-1} \mathrm{de}$ condutividade elétrica do extrato de saturação sem decréscimo de fitomassa seca total; a taxa de decréscimo por unidade de salinidade excedente ao limiar é de $32 \%$.

4. A cultivar de alface "Elba" é 'moderadamente tolerante' à salinidade da água de irrigação na germinação e 'moderadamente sensível' em de plântula e de muda.

\section{LITERATURA CITADA}

Amorim, J.R.A. Comportamento do alho (Allium sativum L.) sob diferentes níveis de salinidade da água de irrigação. Campina Grande: UFPB, 1994. 97p. Dissertação Mestrado

Audry, P.; Suassuna, J. A salinidade das águas disponíveis para a pequena irrigação no sertão do Nordeste: Caracterização, variação sazonal, limitação de uso. Recife: $\mathrm{CNPq}, 1995.128 \mathrm{p}$.

Ayers, R.S.; Westcot, D.W. A qualidade da água na agricultura. Campina Grande: UFPB. 1991, 218p. Estudos FAO Irrigação e Drenagem, 29 revisado

Azimov, R.A. Effects of calcium on dehydrogenese activity in cotton seed germinated in chloride salinity. Voprozy Solensteichivast Rastenii, Tashekent Vzbek, v.1, p.181-188, 1973.

Blanco, F.F.; Medeiros, J. F.; Folegatti, M.V. Produção da alface (Lactuca sativa L.) em ambiente protegido sob condições salinas. In: Congresso Brasileiro de Engenharia Agrícola, 28, Pelotas, 1999. Anais, CD-ROM. Pelotas: SBEA, 1999.

Boursier, P.; Lauchli, A. Growth responses and mineral nutrient relations of salt-stressed sorghum. Crop Science, Madison. v.30,p.1226-1233, 1990.

Brasil. Ministério da Agricultura. Regras para análise de sementes. Brasília: SNDA/CLAV, 1992.365p.

Cramer, G.R.; Alberico, G.J.; Schmidt, C. Salt tolerance is not associated with the sodium accumulation of two maize hybrids. Australian Journal of Plant Physiology, Melbourne, v.21, p.675-692, 1994.

Cramer, G.R.; Spurr, A.S. Responses of lettuce to salinity. I. Effects of $\mathrm{NaCl}$ and $\mathrm{Na}_{2} \mathrm{SO}_{4}$ on growth. Journal of Plant Nutrition, New York, v.9, n.2, p.115-130, 1986.

Doorenbos, J.; Kassam, A.H. Efeito da água no rendimento das culturas. Campina Grande: UFPB, 1994. 306p. Estudos FAO Irrigação e Drenagem, 33

Ferreira, P.V. Estatística experimental aplicada à agronomia. Maceió: UFAL/EDUFAL/FUNDEPES, 1991.437p.

Ferreira, Y.R.P.; Duarte, S.N.; Miranda, J.H.; Medeiros, J.F. Efeito da salinidade de água de irrigação e da lâmina de lixiviação na cultura da alface (Lactuca sativa L.) cultivada em vasos. In: Congresso Brasileiro de Engenharia Agrícola, 27, Poços de Caldas, 1998. Anais. Poços de Caldas: SBEA, 1998. p.106-108.

Filgueira, F.A.R. Cichoriáceas. In: Manual de olericultura. 2. ed. São Paulo: Agronômica Ceres, 1982. p.77-86.

Filgueira, R.F. Efeito de diferentes níveis de salinidade do solo no comportamento de duas cultivares de coentro (Coriandrum sativum L.). Mossoró: ESAM, 1993. 46p. Monografia Especialização

Gervásio, E.S.; Carvalho, J.A.; Santana, M.J. Efeito da salinidade da água de irrigação na produção da alface americana. Revista Brasileira de Engenharia Agrícola e Ambiental, Campina Grande, PB, v.4, n.1, p.125-128, 2000.
Lopes, A.S.; Guidolin, J.A. Interpretação de análise de solo: Conceitos e aplicações. $3^{\mathrm{a}}$ ed. São Paulo: Associação Nacional para Difusão de Adubos e Corretivos Agrícolas, 1989. 50p.

Maas, E.V. Crop tolerance. California Agriculture, Berkeley, v.38, n.10, p.20-21, 1984.

Maas, E.V.; Hoffman, G.J. Crop salt tolerance-current assessment. Journal of Irrigation and Drainage Division, New York, v.103, n.IR2, p.115-134, 1977.

Magalhães, A.C.; Carelli, M.L. Germinação de sementes de feijão (Phaseolus vulgaris L.) sob condições variadas de pressão osmótica. Bragantia, Campinas, v.31, n.5, p.19-26, 1972.

Manchanda, H.R.; Bhandhari, D.K. Effect of presoaking of seeds in salt solutions on yield of wheat and barley irrigated with highly saline waters. Journal Indian Society of Soil Science, New Delhi, v.24, p.432-435, 1976.

Marinho, J.F.L.; Fernandes, P.D.; Gheyi, H.R. Desenvolvimento inicial do abacaxizeiro cv. Smooth Cayenne, sob diferentes condições de salinidade da água. Revista Brasileira de Engenharia Agrícola e Ambiental, Campina Grande, v.2, n.1, p.1-5, 1998 .

Medeiros, J.F. Qualidade de água de irrigação e evolução da salinidade nas propriedades assistidas pelo 'GAT' nos estados de RN, PB e CE. Campina Grande: UFPB, 1992. 173p. Dissertação Mestrado

Nadal, R.; Guimarães, D.R.; Biasi, J. Olericultura em Santa Catarina: Aspectos técnicos e econômicos. Florianópolis: EMPASC, 1986. 187p.

Osaki, F. Calagem e adubação. $2^{\circ}$ ed. rev. ampliada. Campinas, SP: Instituto Brasileiro de Ensino Agrícola, 1991. 503p.

Pereira, J.R. Genótipos de algodoeiro herbáceo (Gossypium hirsutum L. r. latifolium $\mathrm{H}$.) submetidos a estresse hídrico na fase de germinação. Campina Grande: UFPB, 1997. 136p. Dissertação Mestrado

Pizarro, F. Drenaje agrícola y recuperacion de suelos salinos. Madrid: Editora Agrícola Española, S. A. 1985. 542p.

Richards, L.A. (ed.). Diagnosis and improvement of saline and alkali soils. Washington: United States Salinity Laboratory, 1954, 160p. Agriculture Handbook, 60.

Shannon, M.C. In quest of rapid screening techniques for plant salt tolerance. Horticulture Science, Fort Collins, v.14, n.5, p.587-589, 1979.

Shannon, M.C.; McCreigth, J.D.; Draper, J.H. Screening test for salt tolerance in lettuce. Journal American Society of Horticulture Science, Mount Vernon, v.108, n.2, p.225-230, 1983.

Sharma, M.L. Interaction of water potential and temperature effects on germination of three semi-arid plant species. Agronomy Journal, Madison, v.68, p.390-394, 1976.

Silva, E.F.F.; Duarte, S.N.; Furlan, R.A.; Ferreira, Y.R.P.; Miranda, J.H. Utilização de águas com diferentes níveis de salinidade na irrigação da alface. Revista de Horticultura Brasileira, Brasília, v.17, n.3, p.327, 1999.

Viana, S.B.A.; Rodrigues, L.N; Fernandes, P.D.; Gheyi, H.R. Produção da alface em condições de salinidade a partir de mudas produzidas com e sem estresse salino. Revista Brasileira de Engenharia Agrícola e Ambiental, Campina Grande, v.5, n.1, p.62-66, 2001.

Vieira, R.D.; Carvalho, N.M. Teste de vigor em sementes. Jaboticabal: FUNEP/UNESP-FCAVJ, 1994. 164p. 